\title{
ESPACIOS ATRAVESADOS, LUGARES VIVIDOS Y TIEMPOS MATERIALIZADOS: DINÁMICAS LOCALES EN UNA PEQUEÑA CIUDAD MINERA-PIRQUINERA
}

\author{
Pamela Jorquera ${ }^{1}$
}

\section{Introducción}

El presente documento reflexiona en torno a las dinámicas locales de una pequeña ciudad minera-pirquinera ${ }^{2}$ del norte chileno. Dinámicas observadas durante la realización de mi tesis doctoral (2013-2017) titulada "Etnografía de la duración sobre el proceso de envejecimiento y vivencia de la vejez en Inca de Oro, Chile”. La etnografía contempló vivir en el pueblo ocho meses, durante los cuales me enfrenté a diferentes temáticas relacionadas con mi problema de investigación. En este artículo muestro una parte del estudio, específicamente lo referido a las manifestaciones locales transcurridas en los espacios de la calle. Apoyada en la Etnografía de calle (Eckert e Rocha, 2011) presento la esquina de los aburridos, lugar vivenciado en el pueblo y reflexiono sobre sus implicancias dentro de la estructura social de la pequeña ciudad de Inca de Oro.

El artículo se divide en cuatro apartados. En el primero problematizo los enfoques conceptuales para aproximarse a las pequeñas ciudades y a las dinámicas locales. En el segundo presento la esquina de los aburridos y muestro como el tiempo se materializa en ese lugar por medio de la memoria compartida por sus usuarios o habitués (Nunes, 2010). En el tercero reflexiono sobre las tensiones que genera el lugar en la estructura de Inca de Oro. Finalmente, en el cuarto, discuto sobre las implicancias que conlleva el estudio de ciudades pequeñas como Inca de Oro.

\footnotetext{
${ }^{1}$ Universidad de Chile, Chile.

${ }^{2}$ Las personas que realizan esta actividad minera recorren los territorios buscando yacimientos o lugares donde explotar los minerales preciosos, y se les atribuye que, con el paso del tiempo, van perdiendo el sentido de pertenencia a un solo lugar, adoptando ese territorio como hogar, viviendo en libertad sin someterse a nadie. Ese tipo de minero-pirquinero, forma parte de otra forma de entender la minería muy diferente de la figura del operario-minero presente en las explotaciones organizadas a gran escala, como las del salitre, cobre o carbón, entre otros (Arredondo, 2014).
} 


\section{Sobre pequeñas ciudades y su estudio}

Desde una visión político-administrativa Inca de Oro es entendido como una comunidad rural, parte de la comuna de Diego de Almagro que pertenece, a su vez, a la provincia de Chañaral una de las tres que forman la tercera región chilena de Atacama (CENSO, 2002). Inca de Oro es tratada como una comunidad rural con el propósito de relevar las diferencias que tiene en relación a un contexto urbano, las que se basan, principalmente, en criterios demográficos, administrativos y económicos.

Cuando lo rural es entendido de forma general en oposición a lo urbano, sin que sus especificidades sean analizadas, se asocia a una categoría residual que contendrá todo lo que queda por fuera de lo llamado urbano (Rodríguez, Saborio y Candia, 2011). Si bien, actualmente, existe consenso en la necesidad de superar las mediciones dicotómicas de lo urbano y lo rural, como forma de reconocer la heterogeneidad presente en ella, no existe consenso entre los diferentes países en los criterios para estimar la población rural. Haciéndose principalmente en función del número de habitantes y de la ubicación en relación a los límites de las áreas urbanas (Ibid). Así la densidad y la distancia son los dos elementos fundamentales a partir de los cuales se distingue lo urbano de lo rural.

Una forma de problematizarlo anterior es retomar la tarea de la Antropología la que, según De La Pradelle (2007), consiste en elucidar las lógicas implícitas de los actores en una situación dada, que sólo pueden ser develadas por medio de una descripción bien concreta, centrándose en un lugar social e históricamente creado. La autora, entenderá una situación dada como la secuencia de espacio-tiempo que será definida como campo de observación. Este estudio, al hacerse desde un marco antropológico, exigió considerar esas discusiones para tratar Inca de Oro; por lo que se trató lo local como una serie de operaciones, una construcción continua y concentrada de universos prácticos y simbólicos.

En ese sentido, De Certeau (2000) discutió sobre la particularidad de los espacios locales. Señalando que su especificad está dada por la posibilidad de abordar el espacio, es decir, en un contexto local el espacio es posible de conocer no siendo solo imaginado. Así, una característica principal de lo local es la copresencia, el contacto, la experiencia, situaciones todas que se dan en lo cotidiano. 
De Certeau (2000: 129) distinguió entre el concepto de lugar y de espacio. Para él el lugar es el orden, cualquiera que sea, según el cual los elementos se distribuyen en relaciones de coexistencia. El espacio, por su parte, existe en cuanto se toman en consideración los vectores de dirección, las cantidades de velocidad y la variable tiempo. Siendo el cruzamiento de movilidades. A diferencia del lugar, el espacio carece de univocidad y de la estabilidad de un sitio proprio. Así el espacio es el lugar practicado.

En este sentido, la investigación abordó Inca de Oro desde la problematización del tiempo, espacio y lugar mencionados. Seguir ese camino analítico implicó abandonar entender sus dinámicas desde un enfoque rural-urbano, como forma de no caer en análisis dicotómicos ni opuestos; lo rural y lo urbano, la tradición y la modernidad, el interconocimiento y el anonimato, el pueblo y la gran ciudad, la comunidad y el agregado social ${ }^{3}$ (Bozon, 1984: 9).

En el contexto de lo mencionado, el estudio consideró entender a Inca de Oro desde lo que Michel Bozon entendió por petiteville, ciudad pequeña.

\begin{abstract}
Mas s'il y a d'une part des modes de vie, des pratiques sociales, des styles de vie quotidienne relativement fixes, il faut considérer d'autre part l'espace de mise en ouvre des pratiques, la situation particulière et les conditions circonstancielles dans lesquelles les habitus se trouvent inscrits. Dans le cas particulier d'une petite ville, on doit prendre en compte aussi bien la taille de la ville, sa place dans la structure économique nationale, les relations qu'elle entretient avec son environnement rural e urbain, l'écologie urbaine (...) la structure locale des relations entre les groupes sociaux (...) entre les autochtones et les hétérochtones (...) entre les classes d'âges également (1984: 11).
\end{abstract}

El enfoque de Bozon subraya la importancia de comprender los límites de las pequeñas ciudades no como límites cerrados y delineados. Dentro de una pequeña ciudad, los grupos sociales serán definidos por el contacto cotidiano, la coexistencia de los grupos como de los individuos y también por los conflictos que se sucedan. En ese sentido, formar parte de una pequeña ciudad significará estar dentro de una red de interconocimiento, en donde los individuos compartirán un conocimiento y códigos comunes. De saber manejarse en esos códigos comunes, dependerá la pertenencia o no a lo local. Esos códigos estarán dados por los valores compartidos, y por medio de ellos los habitantes de una pequeña ciudad podrán moverse dentro de la estructura social del pueblo.

\footnotetext{
${ }^{3}$ Traducción propia.
} 
La pequeña ciudad de Inca de Oro se caracteriza por la práctica minera como actividad económica principal, principalmente la pequeña minería conocida como pirquinería. Dentro de los estudios hechos en comunidades semejantes (Viezzer; 1978, Gascho; 1982, Eckert; 1985, Vivallos; 2007, Romero; 2011, Eckert; 2012) se establece que las comunidades mineras comparten algunas características, tales como: cultura íntimamente ligada a la historia de la comunidad, identidad surgida en torno al trabajo minero y del producto de extracción, además de las transformaciones a las que deben enfrentar con los cambios en el escenario nacional e internacional. Aspectos propios de esta cultura se entienden por las duras condiciones de trabajo, el peligro y el riesgo constante de accidentes, los problemas de salud crónica, los bajos salarios, el costo ambiental y social producto de la contaminación del aire que produce el trabajo extractivo. Muchas de esas características hacen que las dinámicas locales de esas pequeñas ciudades sean vistas como parte de un mundo tradicional condenado a la extinción frente a los embates de la Modernidad. Lo anterior corresponde a una serie de supuestos que forman un nudo a desatar. En ese sentido este artículo tiene como objetivo mostrar las dinámicas locales sucedidas en la pequeña ciudad de Inca de Oro.

\section{Esquina de los aburridos: lugar donde el tiempo se materializa}

Durante los meses que viví en Inca de Oro, tuve la oportunidad de conocer las diferentes rutinas del pueblo. Así, gracias a las caminadas hechas por sus calles, supe que esos espacios se caracterizaban por ser principalmente masculinos. En ellos era difícil encontrar mujeres. Incluso esa situación era advertida por los interlocutores y algunos me explicaron que el motivo era que las mujeres no se acostumbraban a recibir piropos por parte de los hombres, motivo por el cual evitarían permanecer en esos espacios. De esa forma eran los hombres quienes permanecían en la plaza, las esquinas, los almacenes, conversando entre ellos o solamente observando.

En el transcurso de la Etnografía percibí que las esquinas se constituían como lugares importantes, sobre todo las que se ubican en las calles principales. Eran los hombres quienes se ubicaban en ellas, quienes conversaban o miraban a quien pasaba por la carretera, muchas veces pensé que, su presencia, también se debía a la esperanza de recibir alguna noticia de oferta laboral. De esa forma las esquinas se convirtieron en escenarios de importantes encuentros etnográficos de la investigación. 
A través de la etnografía de calle (Eckert y Rocha, 2011) me di a la tarea de conocer los espacios vividos por los interlocutores e identificar los lugares incanos. Fue así como conocí la esquina de los aburridos, lugar donde la memoria es revivida en conjunto, donde "todos los días en la tarde unos viejitos se ponen a conversar". En la intersección de las avenidas Antonio Matta con Diego de Almeyda se vivencia el lugar, nombrado por los incanos, como esquina de los aburridos.

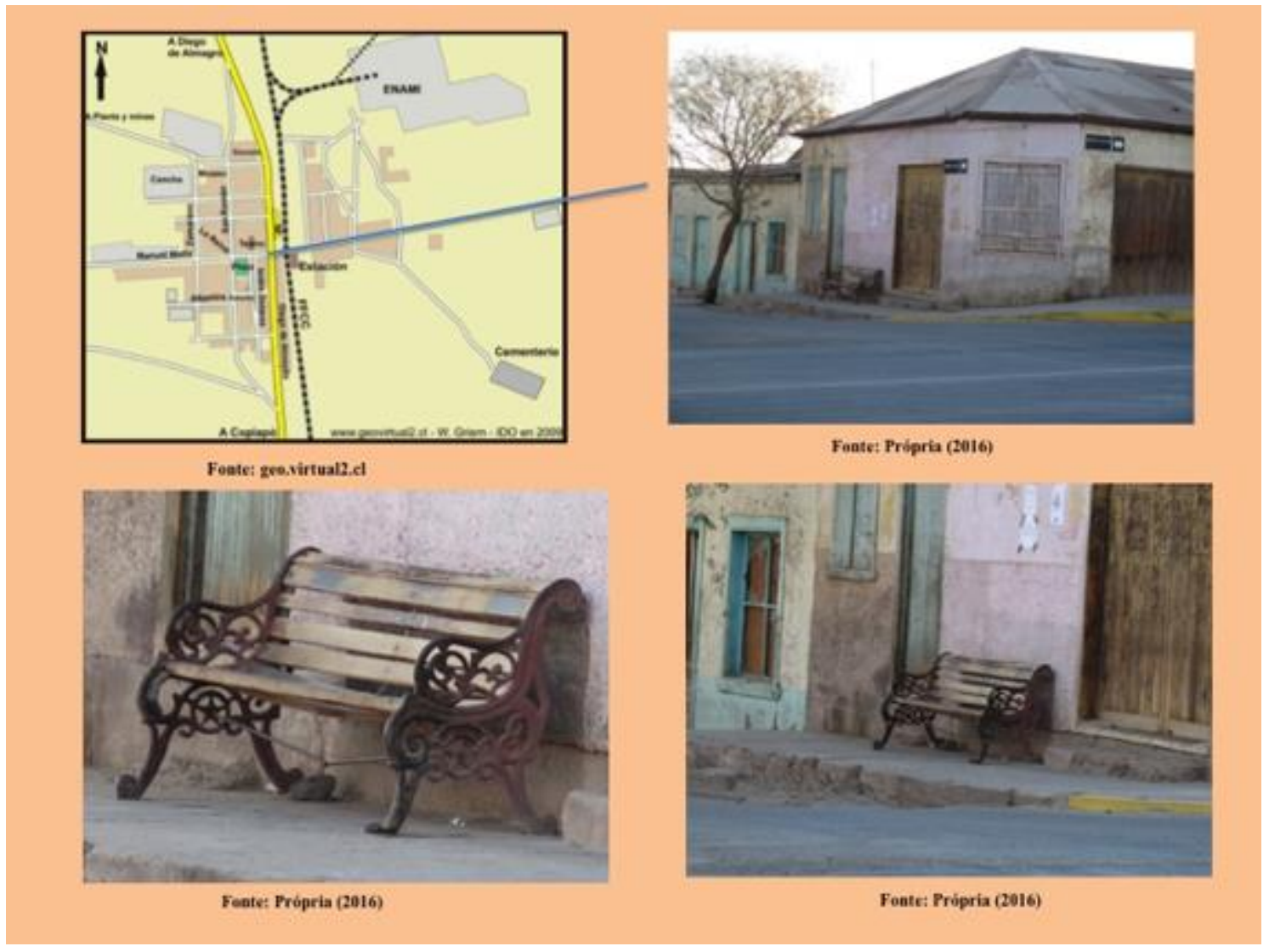

Figura 1: Esquina de los aburridos

Fuente: Elaborado por la autora.

Al comienzo sólo percibí que la esquina era utilizada como un espacio para protegerse del sol, puesto que en la tarde se forma una sombra agradable y, además, hay un banco. Así, primero pensé que la esquina era utilizada para beber, pero después observé que los adultos mayores que se juntaban frecuentemente ahí no lo hacían.

Con el tiempo advertí que el número de habitués de la esquina fluctuaba de tres a cinco personas. Generalmente eran: Don Germán, Don Benito, Don Juan, Don Zacarías, aun cuando su presencia variaba por motivos de trabajo. Una forma que utilicé para saber el tipo de actividad de los adultos mayores habitués de la esquina, fue 
saludarles de mano dada. Generalmente, quien aún trabajaba tenía las manos ásperas mientras que quien no estaban más suaves. De esa forma supe que Don Germán tenía una mina lista para comenzar a excavar. Don Benito trabajaba como guardia nocturno en una empresa cercana al pueblo. Don Juan poseía una tienda de artículos domésticos ubicada en la misma avenida Antonio Matta, al frente de la esquina. Y Don Zacarías cuidaba de sus animales que criaba cerca del pueblo. Don Roberto era el único usuariode la esquina que no realizaba ese tipo de actividades.

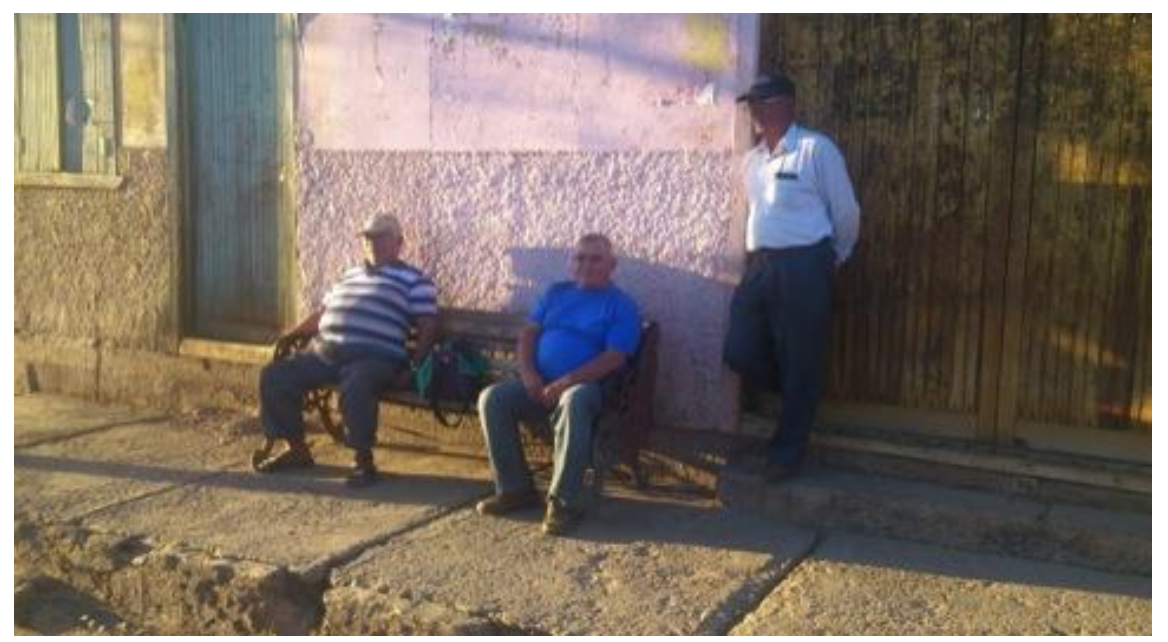

Fotografía 1: Don Juan, Don Benito y Don Roberto (deizquierda a derecha). Fuente: Archivo de la autora 2014.

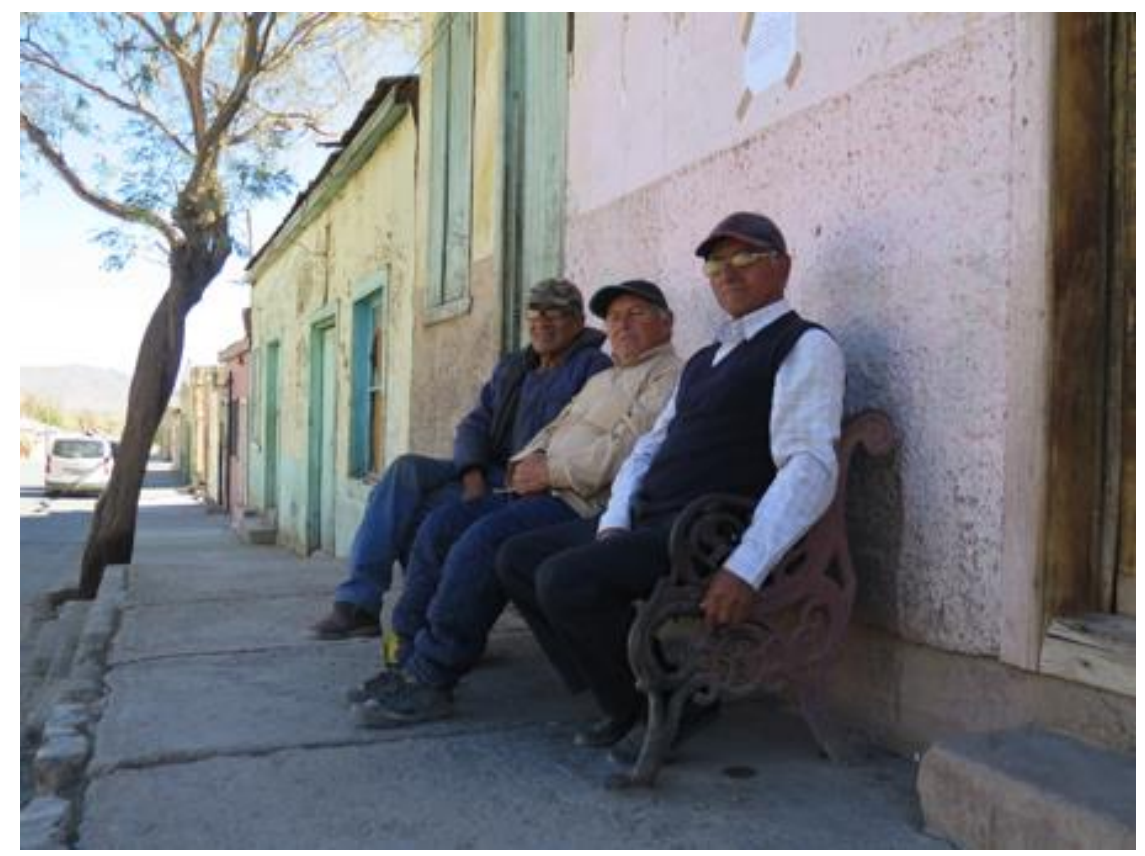

Fotografía 2: Don Marcelo, Don Benito y Don Roberto (de izquierda a derecha). Fuente: Archivo de la autora 2016. 
Todos los habitués de la esquina vivían en el pueblo hacia muchos años, algunos de ellos no habían nacido en Inca de Oro llegando a vivir en él cuando eran jóvenes, principalmente atraídos por el trabajo de la minería en sus cercanías. En nuestras conversaciones me contaron que vivían hacia 50 años por lo que entendí, que la mayor parte de los usuarios de la esquina, habían envejecido juntos, compartiendo una vida hasta llegar a la vejez.

Don Roberto y Don Juan eran muy amigos, casi siempre podía encontrarlos sentados en el banco. Don Roberto se quedaba en la esquina en los horarios previos y posteriores al almuerzo, hasta cuando el sol se ponía, ya que después de eso se enfriaba mucho como para permanecer en la calle. Como la tienda de Don Juan se ubica al frente de la esquina, él se sentaba a esperar a algún cliente, entrando para atender a su clientela o para almorzar o tomar once ${ }^{4}$. Don Benito, hermano de Don Juan y amigo de Don Roberto permanecía en la esquina en algunas oportunidades. Ninguno de ellos nació en Inca de Oro, migrando todos hace mucho tiempo y permaneciendo en el pueblo hasta la actualidad. Por su parte, Don Zacarías y Don Germán son oriundos del pueblo y ambos habían trabajado en la zona de explotación de Minas conocida como Las Guías.

No obstante, a la esquina también llegaban otros habitués. Por ejemplo Don Esteban $^{5}$ a quien le gustaba mucho pasar un tiempo con los demás adultos mayores. Como trabajaba en una mina cercana, fueron pocas las veces que nos encontramos en la esquina, pero cuando aparecía los demás adultos mayores se alegraban mucho. Otros adultos mayores que se sentaban en la esquina eran Don Marcelo, Don Héctor y Don Raúl, aunque su presencia era mucho más esporádica no siendo algo común encontrarme con ellos en ese lugar de Inca de Oro.

Gracias a la relación de confianza y respeto construida junto con los interlocutores, pude sentarme con ellos en la esquina, aun cuando ese lugar era masculino. Compartir tardes y conversaciones que me permitieron entender lo que sucedía en ella y la posición que ocupaba en el pueblo.

La esquina de los aburridos surgía como un lugar relevante de socialización masculina sobre todo para los adultos mayores que, por motivos de salud, no participaban de las actividades sociales desarrolladas en el pueblo, como bingos o bailes, puesto que su horario nocturno los exponía al frio y a enfermedades. En esos

\footnotetext{
${ }^{4}$ En Chile, después de las 18 horas y antes de la cena, se toma una merienda llamada once. Consiste en té, café o leche con pan. Generalmente se acompaña el pan con algo considerado delicioso, como dulce, queso, palta, etc.

${ }_{5}^{5}$ Por motivos éticos se ha optado por nombre un ficticio para ese interlocutor.
} 
encuentros diarios, los adultos mayores de Inca de Oro, tienen un espacio y un tiempo para reactivar la memoria. Sentados uno al lado del otro, en ese banco viejo y raído, los habitués de la esquina comparten diferentes temas, hablan del pasado, del presente, de temas nacionales o locales, pasando el tiempo juntos.

Las veces que me senté con ellos en la esquina, me contaron sobre como era el pueblo antiguamente, muy diferente al actual. Sentados en la esquina, miraban la avenida Antonio Matta y a sus mentes venia la gran cantidad de bares, lugares para jugar, beber y bailar que se ubicaban a lo largo de ella cuando eran jóvenes. Recordaban a las mujeres que trabajaban en esos bares, algunas como garzones y otras como prostitutas $^{6}$. Así esas calles hervían de diferentes personas caminando, comprando, vendiendo, sobre todo cuando los mineros bajaban de las minas y gastaban el dinero ganado después de semanas de arduo trabajo. Los interlocutores de la esquina de los aburridos, me describieron detalles precisos de la infraestructura de las casas y de las actividades que se sucedían en sus interiores, complementándose entre sí. De esa forma traían a la memoria lugares ya extintos como: el salón de billar donde siempre podían jugar y beber, el hospital, o la tienda que fue de Don Esteban y que perdió por negocios desafortunados.

Así, sentarme y compartir el tiempo con ellos me ayudó a conocer el tipo de minería desarrollado en el pueblo, la pirquinería, puesto que era un tema recurrente de nuestras conversaciones. Los habitués me contaban de esa actividad destacando las diferencias con la actividad realizada en la actualidad. La pirquinería se caracterizaba por no tener una organización clara y definida; por ejemplo en la llamada mina vieja trabajaron muchos mineros y las peleas estaban a la orden del día. Incluso los policías de la época, estaban tan acostumbrados a ellas, que cuando comenzaba una entre los mineros les solicitaban que los dejaran descansar un poco antes. Eso porque las peleas eran muy violentas, con cuchillos y con muertos.

Otra diferencia entre la minería de antes y la actual es el esfuerzo corporal que implicaba la explotación de las minas. Don Juan me contó que, en aquellos tiempos, el trabajo era muy rudo "trabajando como si fueran animales, como bestias, 40 o 50 días sin descanso". Muchos adultos mayores pirquineros cuando fueron jóvenes cargaban grandes cantidades de material en sus espaldas para retirarlas de la mina. Situación por la cual ahora, en la vejez, están enfermos y sienten muchos dolores.

\footnotetext{
${ }^{6}$ Los adultos mayores no usaron el término prostituta conmigo, sino mujeres o "aquellas que te hablan de tú”.
} 
Uno de los habitués me señaló que cuando se trabajaba en las minas se hacía con poca ropa porque hacía mucho calor y sudaban mucho. De ese modo, aun cuando hiciera frio o hubiese nieve afuera, los pirquineros salían sin siquiera abrigarse, visto que estaban acostumbrados, incluso, se bañaban con agua fría. Para ellos los jóvenes de ahora no lograrían soportar esas duras condiciones.

Cuando un pirquinero se enfermaba estando en la mina y si no había medicamentos para tratarlos, eran tratados con lo que la naturaleza les ofreciera, con lo que pudieran encontrar en los cerros. Según los interlocutores no era difícil, puesto que en esos parajes encontraban todo lo necesario, ya que ellos habían aprendido eso de "los antiguos", es decir, de sus padres y abuelos. Por ejemplo Don German transmitió sus conocimientos sobre la pirquineria y sobre la naturaleza a sus familiares, pero esa generación no tiene a quien transmitir, puesto cada vez menos jóvenes se interesan por la actividad pirquinera. De esa forma los habitués de la esquina de los aburridos piensan que la actividad morirá con ellos.

Una tercera diferencia, de acuerdo con las conversaciones con los interlocutores, es lo referido a las suntuosas ganancias que se conseguían en la pirquinería. Cuando fueron jóvenes y pirquineaban no pensaron en las ganancias que obtenían, gastando todo, principalmente en alcohol. En esa época, era común que los mineros bajaran de las minas con mucho dinero con el cual compraban ropa nueva. Las viejas que se quitaban las dejaban en el suelo y rápidamente entraban en los diferentes locales a divertirse, en ellos se gastaban todo el dinero hasta no quedar con nada. Cuando eso pasaba hasta debían entregar sus ropas nuevas en parte de pago, por lo que estaban obligados a volver a la calle a buscar entre las ropas viejas tiradas alguna que les sirviera y volvían al trabajo en las minas.

Es por eso que muchos pirquineros me contaron que el minero era tomador y que el dinero ganado era gastado con rapidez. Sobre todo en esa época cuando, en el pueblo, habían muchos bares y muchas prostitutas "habían tantas chiquillas". Don Marcelo me contó cuánto tomaba y lo mucho que le gustaba bailar, gastando todo en los locales de entretención. Me reconoció que cuando era joven y su cuerpo le permitía trabajar, no pensó en su futuro. De hecho para él, ninguno de los pirquineros pensó en el futuro. 
Las interacciones suscitadas en la esquina de los aburridos dan cuenta de la cotidianidad vivida en las calles de Inca de Oro. Los habitués que frecuentan esta esquina pasan el tiempo juntos y conversan. Cuando comparten esos momentos los usuarios de la esquina reviven la memoria que comparten. Siendo Inca de Oro una ciudad pequeña pirquinera se entiende la presencia de personas retiradas de esa actividad $^{7}$. De forma tal la esquina configura un lugar de sociabilidad en la cual los adultos mayores habitués experimentan su vejez y vivencian lo local. Dicha esquina constituye un lugar en el cual los adultos mayores de Inca de Oro duran, es decir, donde su memoria es revivida. El caso descrito muestra, cómo los adultos mayores habitués de una pequeña ciudad minero-pirquinera comparten experiencias socioculturales comunes sobre las cuales negociaron sus proyectos de vida particulares. (Velho, 2013).

La memoria contenida en ese lugar no solo muestra la importancia de lo qué es recordado, sino también la forma cómo es recordado (Halbwachs, 2011). La memoria de los pirquineros retirados es construida en la participación de ese grupo de adultos mayores que frecuenta la esquina de Antonio Matta con Diego de Almeyda. En esa participación cada uno de ellos vive un sentimiento de simultaneidad en las experiencias comunes. Lo que se ve favorecido por la presencia de quienes con los que se ha envejecido; puesto que en esa esquina los adultos mayores no se encuentran con desconocidos, como podría suceder en un contexto de ciudad mayor.

La memoria construida y compartida por los usuarios de la esquina revela un pasado que se superpone al presente, no siendo independiente de la experiencia presente dado por el acto de recordar, experiencia que hace surgir esa memoria. En ese sentido no es posible decir que pasado, presente y futuro constituyen, una cuando se trate de diferentes palabras, un único y mismo concepto, que solo en la experiencia humana existen con líneas demarcadas (Elias, 1998: 62).

Solamente en el presente los adultos mayores habitués de la esquina, seleccionan los eventos que irán a recordar. En esa selección, hecha por los usuarios de la esquina existirá una intención, un propósito, es decir, los adultos mayores recuerdan de forma jerárquica (Eckert e Rocha, 2011). Es por ese motivo que describí los acontecimientos recordados, los temas sobre los cuales se habla. Apareciendo así los valores de la pequeña ciudad de Inca de Oro, de su actividad pirquinera; como el valor de la honra, el valor del esfuerzo y el coraje que les demandó en su juventud. A través de la

\footnotetext{
${ }^{7}$ No utilizo la palabra jubilado puesto que no existen jubilados de la pirquinería, ya que ninguno de los pirquineros impuso durante sus años de trabajo.
} 
memoria revivida en la esquina de los aburridos, los adultos mayores pirquineros se proponen durar, y para durar en el tiempo, necesitan que la actividad sea conocida por las nuevas generaciones, la pirquineria los debe transcender ${ }^{8}$.

\section{Esquina de los aburridos: cronotopo de edad en lo cotidiano}

Escuché esa expresión por primera vez a una de mis interlocutoras y quedé confundida, pues no sabía a qué esquina se estaba refiriendo. Gracias a la etnografía de calle ya había identificado la esquina como un lugar de importancia en el pueblo, pero no conocía el nombre dado por los incanos. Después el nombre me fue rebelado por otro incano, en una ocasión en la cual se enfrentó a los adultos mayores, exigiendo que me dijeran el nombre. En esa oportunidad, todos permanecieron en silencio y solo Don Roberto protestó, aclarando que solo se sentaba en el banco, pero que no pertenecía a la esquina. Esa escena etnográfica me mostró la incomodidad que provoca en una pequeña ciudad como Inca de Oro el lugar de la esquina de los aburridos.

La esquina de los aburridos es un lugar que no pasa inadvertido en el pueblo, generando molestia por la falta de actividad que representa. El nombre dado por los incanos a la esquina se relaciona con la intención de evidenciar la falta de actividad de sus usuarios, en el sentido de la falta de interés para realizar alguna actividad. La inactividad no es aceptada en una pequeña ciudad donde el trabajo es altamente valorado, sobre todo en la construcción de los proyectos de vida de los hombres (Velho, 2013). De hecho, algunos habitués bromeaban conmigo refiriéndose a la esquina como su oficina.

No obstante, hay otras dimensiones con las cuales, los incanos, no se llevan bien. Para profundizar en esto considero pertinente la categoría analítica desarrollada por Teresa del Valle, quien trabaja los cronotopos genéricos.

Los cronotopos genéricos se definen como una estrategia metodológica que facilita el acceso a interpretaciones más amplias acerca de los sistemas y relaciones de género. Están relacionados, a su vez, con formas de memoria no discursiva (del Valle, 1999: 211).

\footnotetext{
${ }^{8}$ Corresponde al principal motivo por el cual muchos de los interlocutores aceptaron ser parte de la investigación.
} 
Los cronotopos sintetizan significados mayores, correspondiendo a enclaves temporales, con actividades y significados complejos en los cuales se negocian las identidades; en ellos también es posible negociar o reafirmar identidades. Para dicha autora (1999) un tipo específico de cronotopo son los genéricos, es decir, aquellos puntos para los que convergen el espacio, el tiempo y el género. Así el género crea y recrea identidades y desigualdades.

Para encontrar un cronotopo genérico Del Valle señala que es posible identificar situaciones en las cuales se definan o se expresen las identidades. Por ejemplo, situaciones en las cuales se construyen las normatividades y los estereotipos que influirán, a largo plazo, en la construcción de lo que es femenino y masculino.

En el caso de la esquina de los aburridos estamos delante de un cronotopo genérico, puesto que corresponde a una situación en la cual se construyen las normatividades y los estereotipos de género. Los hombres dominan el espacio público de la calle, aun cuando deberían estar trabajando y no "haciendo nada". Según lo mencionado por Bozon, "los lugares no privados tienden a ser apropiados por grupos sociales, grupos de sexo, etc.” (1984: 74) ${ }^{9}$. Además de eso, la esquina de los aburridos permite identificar otro tipo de cronotopo, uno de edad.

La esquina constituye un espacio posible de ser identificado por los significados atribuidos a la edad, considerando que corresponde a un espacio de sociabilidad de hombres adultos mayores. En esa esquina converge el espacio, tiempo, género y edad. Son los adultos mayores quienes dominan el espacio público porque es en la vejez cuando se espera la inactividad de las personas, aun cuando esa falta de actividad sea criticada por el resto de los incanos.

En la esquina de los aburridos se negocian las identidades de los adultos mayores, catalizando realidades y sistemas mayores y complejos en los cuales ser adulto mayor, sin alguna actividad productiva, genera molestia. Esa situación se agudiza al reconocer en los adultos mayores, personas retiradas de la pirquinería, actividad que se caracteriza por el coraje y por el valor del esfuerzo.

De esa forma, la esquina de los aburridos apunta a otra dimensión definidora de los cronotopos según del Valle: las experiencias que se corporifican en la memoria como parte vital de la existencia. Es decir, la dominación de la calle por parte de los

\footnotetext{
${ }^{9}$ Traducción propia.
} 
cuerpos masculinos es aceptada e, incluso, naturalizada. Aun cuando la presencia de los cuerpos masculinos de adultos mayores en la calle genera incomodidad en el pueblo.

En el contexto de Inca de Oro, el cuerpo masculino performativa (Butler, 2013) la actividad económica de la pirquinería, la que es valorada por el esfuerzo y el coraje que los pirquineros posen a la hora de explotar las minas. En la región de Atacama es común destacar la bravura, fuerza, y coraje del pirquinero.

Para Butler (2013) el género no es sustantivo, es decir, no da cuenta de una serie de cualidades o características. Eso porque las cualidades son producidas al interior de una estructura social especifica. Por lo tanto, las características de género no pueden ser vinculadas a una identidad preexistente de hombre y mujer.

\footnotetext{
Nesse sentido o gênero sempre é um feito, ainda que não seja obra de um sujeito tido como preexistente à obra. Assim não há identidade de gênero por trás das expressões do gênero, essa identidade é performativamente constituída pelas próprias expressões tidas como seus resultados (Butler, 2013: 48).
}

Así, desde Butler se puede percibir que los atributos del cuerpo pirquinero masculino han sido construidos a lo largo del tiempo al interior de la estructura social incana, de tal modo, que ese cuerpo pirquinero masculino fue estilizado repetidamente, llegando a cristalizarse como la esencia de la actividad. El cuerpo, en la concepción de dicha autora, no debe ser observado como un medio pasivo sobre el cual se han inscrito los significados culturales, sino que debe reconocerse la propia construcción social de ese cuerpo (2013: 194).

En síntesis, en la pequeña ciudad de Inca de Oro el cuerpo masculino performativa las cualidades atribuidas a la actividad pirquinera. A partir de eso, el cuerpo pirquinero del adulto mayor no representaría la pirquinería, no daría cuenta de sus cualidades, no transmitiría la honra de la actividad. Por medio de esos cuerpos, la pirquinería no puede performativar el orgullo. Aún más, los cuerpos masculinos de los adultos mayores pirquineros, ubicados en ese lugar de la calle, la confronta, poniendo en cuestión la bravura, el coraje, y evidenciando el paso del tiempo en esos cuerpos masculinos, y las consecuencias dejadas en ellos por la actividad.

A partir de la perfomatividad de los cuerpos, discutida por Butler, también es posible percibir las relaciones de poder implicadas en esa esquina, así el factor sexo forma parte de un medio discursivo/cultural de poder sobre el cual la cultura actúa (Butler, 2013: 25). La forma de tratar la vejez formará parte de un discurso/cultural de 
poder sobre el cual la cultura actuará. En ese sentido, la incomodidad generada por el cronotopo de edad que evidencia la esquina de los aburridos, forma parte de las relaciones de poder en Inca de Oro, donde la juventud es valorada, sobreponiéndose a la vejez, el cuerpo pirquinero masculino joven es el deseado en detrimento del cuerpo del pirquinero adulto mayor. Según Bourdieu, las clasificaciones de edad (y las de sexo o de clase) siempre ponen límites que producen un orden en el cual cada uno debe mantenerse, cada uno debe ocupar su lugar (2002: 164). De ese modo en la pequeña ciudad de Inca de Oro, uno de los lugares para los adultos mayores es la esquina de los aburridos.

\section{Consideraciones finales}

La investigación que dio origen a este artículo trató sobre la vivencia de la vejez en la vida cotidiana de los adultos mayores que viven en la pequeña ciudad de Inca de Oro. A través del análisis de la esquina de los aburridos mostrado, se evidencia cómo en el contexto de la sociedad compleja subsisten contextos diferentes que revelan la heterogeneidad que caracteriza a nuestras sociedades.

Lo mostrado en este documento muestra distinciones que pueden ser consideradas traspasadas o superadas pues forman parte de un mundo considerado tradicional en camino a la extinción. En ese sentido José de Souza Martins (2008: 18) señala que la modernidad incorpora el mundo tradicional que nada tiene de moderno, incorporando sus relaciones sociales, sus relaciones de género y sus relaciones intergeneracionales, contrario a la visión de la modernidad como sinónimo de progreso y antónimo de lo tradicional.

Las vivencias de la pequeña ciudad de Inca de Oro, narradas por medio de la esquina de los aburridos, se encuadran en las características de las sociedades industriales, existiendo una fuerte regulación normativa de los discursos, de las prácticas y de las normas por medio de las cuales los individuos pueden transitar. En el caso de los habitués de la esquina, se advierte una sociedad que centra los proyectos de vida de sus individuos en torno al trabajo y las tensiones que genera en ellos cuando esos individuos quedan fuera de ese mercado. Eso se agudiza en una pequeña ciudad como Inca de Oro, puesto que su estructura está atravesada por valores que privilegian el trabajo, la actividad y el esfuerzo. 
Los adultos mayores habitués de la esquina de los aburridos vivencian su cotidianeidad en espacios, lugares y tiempos socialmente aceptados para ellos, sobre todo lo que se relaciona con el espacio público de la calle, aun cuando son criticados por esa permanencia por la falta de actividad que representa. Así esas dimensiones están atravesados por los valores propios de la estructura social incana.

La sociabilidad de los adultos mayores en la esquina en cuestión se caracteriza por la confianza, dado que forman parte de una gran familia con la cual la vida se ha compartido y con quienes se construye una memoria que siempre puede ser activada, reforzando el sentimiento de pertenencia, de intimidad, de familia. Esa memoria no puede ser separada de los habitués de la esquina, constituyendo parte fundamental de lo que es vivenciar la vejez en Inca de Oro.

La etnografía llevada a cabo, además, permite reflexionar en torno al quehacer antropológico en contextos pequeños. Así estudiar una pequeña ciudad exige entenderla dentro de su contexto mayor para entender su estructura y los valores presentes en ella. En ese sentido Inca de Oro comparte códigos con otros contextos mineros y un ethos particular presente en el territorio mayor del norte chileno, territorio de histórica tradición minera. En el contexto de la sociedad contemporánea, es difícil pensar una comunidad aislada, aun cuando nos enfrentemos a una pequeña ciudad considerada condenada a la extinción, aun cuando para el visitante o para el transeúnte de esos páramos producto de sus casas viejas, ventanas y puertas cerradas, pueda parecer un pueblo donde nada sucede, un pueblo fantasma. Un pueblo que sólo se abrirá si le damos el tiempo de expresarse. Así, acompañar las vivencias de los habitués de la esquina de los aburridos significó tiempo para seguir el propio ritmo de sus usuarios y no imponer los propios, mucho más acelerados.

Hacer Antropología en pequeñas ciudades, también, implica un desafío ético importante, puesto que en una ciudad donde todos se conocen es difícil identificar el punto donde el conocimiento construido con los interlocutores puede ser revelado. Aun cuando se utilicen nombres ficticios no se asegura el anonimato, ya que la red de interconocimiento de los habitantes de una pequeña ciudad es mucho más profunda de lo que un investigador -un advenedizo- puede conocer. En este sentido, la propuesta ética de la Etnografía de la duración ayudó a pensar esa cuestión, ya que otorgó un lugar central a los interlocutores como constructores del conocimiento, dialogando y debatiendo los hallazgos. 
Finalmente, y en esa línea, cabe destacar que las vivencias narradas de la esquina de los aburridos, permitió a los interlocutores durar en el tiempo, ya que a través de sus vivencias la pirquinería podrá ser conocida. Para estos adultos mayores, que se consideran los últimos pirquineros, es muy importante que su memoria se active, dure y vibre en la sociedad compleja contemporánea.

\section{Referencias}

BOURDIEU, P. La 'juventud' no es más que una palabra. En Sociología y cultura. Grijalbo, 2002, p. 163-173.

BOZON, M. Vie quotidienne et rapportssociauxdans une petiteville de province. La mise en scène des différences. Pressesuniversitaires de Lyon. 1984.

BUTLER, J. Problemas de gênero. Feminismo e subversão da identidade. Civilização Brasileira. 2013

CERTEAU, Michel de. "Andares de la ciudad y Relatos de espacio", en $L a$ invención de lo cotidiano I. México, ITESO. 2000.

De La Pradelle, M. (2007): La ciudad de los antropólogos, en Cultura Urbana, № 4. Chile.

ELIAS, N. Sobre o tempo. Jorge Zahar Editor. 1998

ECKERT, C. E ROCHA, A. Etnografia da duração nas cidades em suas consolidações temporais. Revista de CienciasSociales, $\mathrm{N}^{\circ}$ 34. 2011 107-126. Disponível em: periódicos.ufpb.br

ECKERT, C. Os homens da mina: Um estudo das condições de vida e representações dos mineiros de Carvão em Charqueadas/RS. Dissertação como requisito para obtenção do grau de Mestre em Antropologia. Ppgas. UFRGS. 1985

ECKERT, C. Memória e Trabalho: Etnografia da duração de uma comunidade de mineiros de carvão (La Grand-Combe, França). Porto Alegre. Editora Appris, Brasil, 2012.

GASCHO, T. A pirita humana. Os mineiros de Criciúma. Dissertação (Mestrado em Ciências Sociais) - Universidade Federal de Santa Catarina, 1982.

HALBWACHS, M. Memoria colectiva y memoria histórica. 2011.

INE. CENSO: Instituto Nacional de Estadística, 2002.

MARTINS, J. A sociabilidade do homem simples. Editora Contexto. 2015.

NUNES, R. A "Boca", a "Esquina" $e$ o "Recanto": sociabilidade, cotidiano $e$ memória entre aposentados habitués do Centro de Santa Maria, RS. Dissertação como requisito para obtenção do grau de Mestre em Antropologia. Ppgas. UFRGS. 2010

RODRÍGUEZ, A., SABORIO, M. y CANDIA, D. Elementos para una mejor medición de lo rural en América Latina. En Nueva agricultura, territorio y sociedad. Enfoques sudamericanos. Revista paraguaya de Sociología (pp. 25-56). Paraguay.2011

ROMERO, I. Pirquineros del Oro de la Sierra Jesús María: Una mirada etnográfica. Memoria para optar al título de Antropólogo Social. Universidad de Chile. 2011.

VALLE, del T. Procesos de la memoria: cronotopos genéricos. Universidad del País Vasco. 1999

VELHO, G. Projeto, emoção e orientação em sociedades complexas. In: Velho, Gilberto. Um antropólogo na cidade. Rio de Janeiro, Zahar. P. 2013, p. 87 a 109. 
VIEZZER, M. "Si me permiten hablar..." Testimonio de Domitila una mujer de las minas de Bolivia: Siglo XXI Editores S.A, 1978.

VIVALLOS, C. Trabajo, Envejecimiento y Exclusión. Trayectorias laborales de exmineros del carbón de Lota. 2007. Tese (Mestradoem Antropología y Desarrollo) Universidad de Chile, Santiago, Chile, 2007.

Recebido em: 20/10/2017. Aprovado em: 15/11/2017. 